\title{
Marketing Strategy of Tourism Based on the E-commerce Environment
}

\author{
Yeqian Ni, Libo Wen, Bin Huang \\ School of Media Studies \& Humanities, Zhejiang University City College \\ Hangzhou, 310000, China \\ E-mail:nyq217@163.com
}

\begin{abstract}
In the e-commerce environment, some current situations still exist in the development of China's tourism, such as the single marketing tool, the unclear direction of development in the tourist websites, the low level of personalized products, imperfect legal system and payment platform, delayed information delivery. This essay aims at exploring how to combine traditional and interactive marketing, clearing the direction, refining the business segments, providing a personalized service, effectively combining tourism and mobile e-commerce, forming an optimized marketing strategy of development.
\end{abstract}

\section{Key words: E-commerce; Tourism; Marketing Strategy}

*Yeqian $\mathrm{Ni}$ is the first author; Libo Wen is the correspondence author; Bin Huang is the instructor.

Tourism, coined as 'everlasting rising industry' , is expected to be the backbone of a country, and develop along with economic progress. However, the single traditional tourism fails to meet the diverse demand brought about by the clients. Fortunately, such demand is catered by the advent of tourism-oriented e-commerce. As an online giant of global travel and hotspot of risk investment, e-commerce in tourism is growing in an unprecedented pace and many travel-related enterprises have been participating in ecommerce.

\section{THE STATUS QUO OF THE DEVELOPMENT OF CHINA'S TOURISM E-COMMERCE.}

According to WTTC, the tourism and travel industry of China are expected to enjoy a great prosperity in the next 10 years with an estimated growth rate of $10.9 \%$. In terms of the promotion of economic development, tourism has made a huge contribution to GDP, which will amount to 840 billion Yuan in 2013. As is predicted in the National Tourism Administration, the total income of tourism will be 3.3 trillion Yuan in 2020, which is equivalent to 8\% of GDP and it will become a true pillar industry of the national economy.

There are rich tourist resources and many places of interest in China. It plays an important role in the mobilization of domestic demand and promotes economic development. With the deepening of reform and opening up and the opportunity to join the WTO, great changes have taken place in tourism, especially the rapid development of tourism e-commerce.
In addition, according to 'the 30th China Internet Development Statistics Report' released by the China Internet Network Information Center (CNNIC) in Beijing, it shows that, at the end of June 2012, the number of Internet users in China reached 538 million. The rate of internet popularization was $39.9 \%$, among which mobile phone netizens reached 388 million, more than the 0.38 billion of desktop computers users.

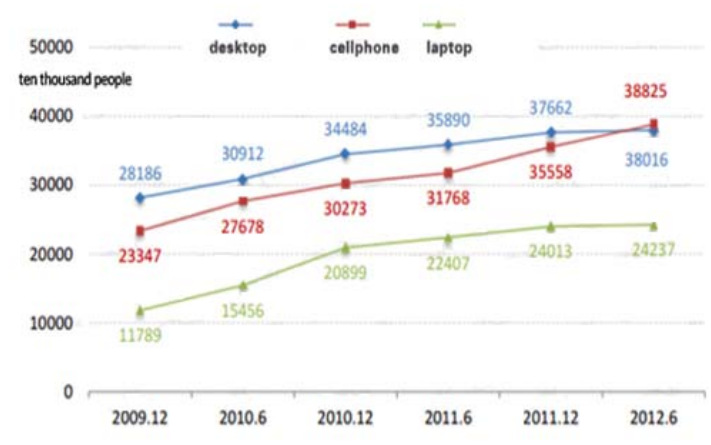

Figure 1. The scale of netizens using in different terminals

From the table above, along with the decline of the internet users with desktop and notebook computers, mobile phone netizens have increased. The growing popularity of intelligent terminals and the wide application of mobile communication network make the mobile tourism ecommerce, especially the mobile terminals application platform become the battleground of tourism e-commerce enterprises in the future.

The continuously increasing number of netizens and demand for travel caused the growth of various tourism websites.

There are four categories of travel site in Chinese market: Travel Channel of Portal (Sina, Sohu, ect.), Self-built website of tourism enterprises, such as ly-mh.com, Professional travel sites, such as Ctrip Travel Network, which generally has the background of venture investment. Government class website, such as the Qingdao government network which itself is not engaged in the travel business but in building a "e-commercial tourism building" in order to offer an e-commerce platform for tourism enterprises and solve the problems of business marketing. And many of which can be classified according to the content and business model: 
TABLE I. FAMOUS REPRESENTATIVES IN ONLINE TRAVEL MARKET

\begin{tabular}{|l|l|}
\hline Type & Representative \\
\hline \multirow{2}{*}{$\begin{array}{l}\text { direct distribution from airline } \\
\text { companies }\end{array}$} & AIR CHINA \\
\cline { 2 - 2 } & CSAIR \\
\hline direct distribution form hotels & 7 Days Inn \\
\hline travel service online & ctrip.com、 elong.com \\
\hline $\begin{array}{l}\text { online service of traditional } \\
\text { travel suppliers }\end{array}$ & mangocity \\
\cline { 2 - 2 } online tourism platform & aoyou (CYTS) \\
\hline vertical search & $\begin{array}{l}\text { B2C platform: trip.taobao.com、 } \\
51766 . c o m 、 \text { chn.lotour.com }\end{array}$ \\
\cline { 2 - 2 } & B2B platform: 17u.cn \\
\hline user reviews website & qunar.com、 kuxun.cn \\
\hline professional recommendation & daodao.com \\
\hline
\end{tabular}

As is shown in the statistics of Iresearch, the online tourism market kept on the rapid rise in the second quarter in 2012 compared with the year before. The amount of the transactions reached at 41.87 billion Yuan, which was $35.8 \%$ higher than that of last year.

Chinese online travel industry shows such a trend of steady growth, because there are two main reasons: First, the steady increase of the proportion of natural growth, as well as online booking of air ticket market; second, the hotel's OTA online distribution and the direct marketing in economy end hotel chains remain rapid growth.

\section{THE CURRENT MARKETING SITUATION OF TOURISM- ORIENTED E-COMMERCE WEBSITE IN CHINA}

\section{A. The Imperfect legal system and the unsound payment platform.}

Tourism e-commerce is an emerging industry. Its length of development in China is not longer than that of Europe and America, and the operation is not mature enough, especially the related laws and regulations are not limited. Our existing e-commerce legislation is only one aspect of the legislative norms, such as the 'Contract Law', 'People's Republic of Computer Information System Security Protection Ordinance', etc. It lacks a complete specification system, which is not conducive to the development of ecommerce in China.

At present, there are some mature third-party payment platforms in Chinese market, such as Alipay, Tenpay, the major banks' online banking systems. But the imperfect payment platform makes false information released, funds stolen, personal information leak, which directly hinders the further development of tourism e-commerce.

\section{B. Unsettled direction of development of the travel web sites, and the low level of personalized products}

Most of the Portals in China are involved in tourism projects, and has its own tourism sector. But the poor integration results in overloaded information so that to customers the received information is quite little. In the professional travel websites, although the information and the ideas of business-to-business is ore clear, but some problems, like its low access, lack of funds and lower customer confidence, make its numbers of customers hard to counter traditional travel agencies.

Besides, a large number of homogenization of the products appears which makes it uneasy to distinguish with all kinds of website business, and leads to the less competitiveness. Meanwhile it is difficult to meet the individual needs of the customers, and customers can not customize personalized products.

\section{Delayed and asymmetric message delivery of tourism information}

Before traveling, customers can find out the tourist destinations in advance through BBS, travel web sites, relatives and friends and other ways, and they can select and adapt travel routes suitable for themselves.

But even you have acquired a lot of information, variability and non-fixity of the tourism situation also makes it impossible to obtain instant information during the course of traveling. For example, if there is an unexpected cost demanding in the travel process, it will inevitably pay consulting fees and additional costs for itself, which disobeys the customers' thoughts.

The asymmetry and lag of travel information makes consumers' demand difficult to be satisfied. Meanwhile tourism e-commerce websites also lose a further opportunity to get profits.

\section{Single modes of marketing}

In Recent years, Chinese tourism e-commerce websites, especially Ctrip, Elong, Mango, Tongcheng the four OTA websites frequently initiate a price war in order to attract customers and do marketing. However this kind of marketing often fails to reach the initial purpose of the enterprises, and it's more likely to make the quality of service difficult to guarantee, even reduce the loyalty of the customers. In addition, the unattractive web pages only draw a few travelers, who take the initiative to resort to the websites and seek services.

\section{THE MARKETING STRATEGY OF TOURISM IN E- COMMERCE ENVIRONMENT.}

\section{A. Improving the legal system, cooperating with the third- party payment platform closely.}

To be in the initiative position in the development of economy and science and technology, the government should set a complete feasible law on e-commerce, try to avoid the defects like delayed development and uncertainty of legal system. At the same time, the coordination among the tourism e-commerce enterprise, band and government departments should be improved.

Enterprises should cooperate with the third-party payment platform actively, especially the bank, in order to contribute to providing credit guarantee for its enterprises' 
internet marketing, which increases customers' trust and reduces the operation cost of tourism websites.

\section{B. Clearing development direction, classifying, providing personalized service}

Different types of tourism e-commerce websites should focus on different areas of development refine the classification of tourism business and avoid oversize to fail to provide professional services. Professional travel website services are mainly for individual and group travel. They should provide one-stop services, meet customers from all aspects, including the provision of air tickets, hotel reservations, tourist routes and booking a holiday products, etc. The website of tourism enterprises which are designed by them should display their own advantages, combine with tourism resources from the headquarters and develop focus on tourist products. The government websites should provide network platform competitiveness for medium and small-sized enterprises with equitable principles.

They can also make up for the deficiency and improve the comprehensive competitiveness by combining ecommerce enterprises, integrating resources, enlarging their own advantages. Besides, they need to change the mechanism in time, broaden financing channels, cooperate with foreign large-sized tourism websites, strengthen the capacity of capital operation.

\section{Strengthening the combination between mobile e- commerce and tourism}

Mobile e-commerce is an e-commerce which uses mobile phone, PDA, palm computer and other wireless terminals to do a B2B, B2C or C2C. It unites the Internet, mobile communication technologies perfectly; it makes people do all kinds of business at anywhere and anytime. It makes it possible to do transactions online or offline and online and makes e-payment and various trading activities, business activities, financial activities and related service activities come true.

Mobile e-commerce does well in providing real-time information and solving information asymmetry in the process of tourism. It offers personalized service without the limit of time and space.

\section{Combination of traditional marketing and interactive marketing.}

According to the survey analysis, the tourists are informed of online travel company from the website advertising(61.1\%), friends and family recommending(56.6\%), newspaper, magazines, advertising(36.0\%), search engines(26.9\%) and television advertising(24.2\%), particularly website advertising, friends and family recommending, so travel websites should perfect their advertising and word-of-mouth marketing, such as producing an excellent web advertising, increasing online communication services, questionnaires, etc. Thus the strategy and tactics could be changed in time and products and services which meet consumers could be introduced at any time.

In addition, the growth rate which was more than $100 \%$ in the first half of 2011 belongs to micro blog and shopping online. What is more, the growth rate of micro blog was $208.9 \%$ in half year, and the number of users added up to 195 million in June 2011.

Microblogging, which is so called Micro blog, is based on users' information-sharing, disseminating and access platform. Users can update information within about 140 words of text and share instantly through WEB, WAP and personal community with different client components. Micro blog gradually occupies the market of e-commerce marketing because of its large amount of information and low cost. This is a marketing platform full of interactivity. People can fully feel the interaction between business and consumers. Micro blog as an interactive marketing can not only be able to interact with the customers, but also be able to generate sales. The final goal of user interaction is to raise the reputation. In the United States, many companies open account specializing in Facebook and Twitter. Many years ago, some travel companies fraudulently bought and sold in network traffic while other new formats used micro blog, SNS to do marketing. Micro blog as Chinese largest instant network platform will become a sales platform in the future.

Network group purchase, which innovates e-commerce channel in the consumption, appears suddenly as a new commercial retail. Group purchase of traveling, an important part of consumption, not only becomes the hot products, but also develops into a group purchase in a vertical way, becoming the key phenomenon in Tourism Ecommerce.

\section{REFERENCES}

[1] China Tourism Academy," The Report on the Development of China's Tourism E-commerce,"2011

[2] China online travel market and development trend of paper research group," The paper of on-line tourism marketing trend in China,"August.2012

[3] iResearch Survey Co. Ltd," annual examining report on on-line tourism in China,"July.2012

[4] X.W.Zhou," The Existence and Development of China's small and medium-sized E-commerce enterprises on tourism," China ECommerce,May.2012.pp.39

[5] F.R.Huang," The Analysis of the Market Structure of China's Tourism E-Commerce,” China E-Commerce.,June.2011.pp.10-12

[6] N.Du, "The Brief Analysis of the Current Situation of Tourism Ecommerce,” The Northern Economy and Trade,2012

[7] D.R.Chen, S.Z.Zhang, L.H.Xu, "The Cases and the Analysis of Ecommerce, "Higher Education Press, May.2010.pp.345-346

[8] Y.M.Wu, "The Brief Introduction on the Establishment of Ecommerce Legal System," China Business and Trade,April.2012,pp.242-243

[9] C.Cao, "The Brief Analysis on the Strategy of E-Commerce in Tourism," Daguan Weekly,2012.pp.116-1 